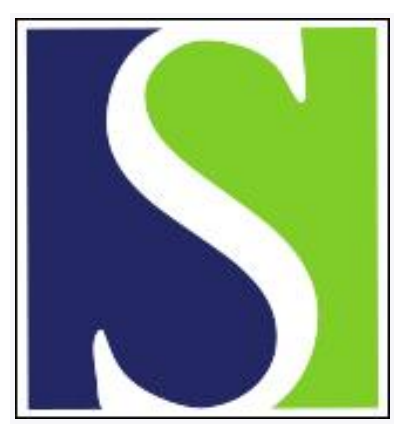

Scand J Work Environ Health 1980;6(2):135-145

https://doi.org/10.5271/sjweh.2622

Issue date: Jun 1980

The effect of welding fumes on ocular readaptation time.

by Linde C-J

Key terms: central nervous system; effect; ocular readaptation time; optokinetic nystagmus; welding; welding fume

This article in PubMed: www.ncbi.nlm.nih.gov/pubmed/7433949

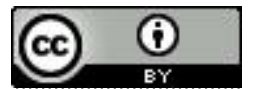




\title{
The effect of welding fumes on ocular readaptation time
}

\author{
by Claes-Johan Linde, MD ${ }^{1}$
}

\begin{abstract}
LINDE, C-J. The effect of welding fumes on ocular readaptation time. Scand $j$ work environ health 6 (1980) 135-145. The effect of welding fumes on ocular readaptation time (RAT) has been investigated. Objective measurements of RAT were obtained from a determination of the recovery time for optokinetic nystagmus following a bright flash of light. Welding electrodes of different types and chemical compositions were used. Welding fumes and the breathed gases were analyzed for particles, and the blood concentration of certain trace elements was determined. The results show that fumes from basic electrodes, containing high amounts of calcium and fluorides, and sometimes copper, produced a marked increase in RAT. The fumes from rutile electrodes, containing only low amounts of these substances, produced no demonstrable prolongation of RAT. Nor was RAT affected by the copper content of the electrodes. Thus the results appear to indicate that fluorides in the fumes produced by the basic electrodes cause the prolongation of RAT. The substances causing this prolongation seem to be bound to fume particles greater than $0.3 \mu \mathrm{m}$. Discomfort - nausea and headache correlated with increased RAT prolongation. But analyses of the ambient air and of trace elements in the blood did not reveal any changes that could be correlated with the effect on RAT. RAT changes measured in conjunction with the inhalation of fumes from basic electrode welding are comparable to those seen after the intake of a therapeutic dose of oxazepam.
\end{abstract}

Key terms: central nervous system, ocular readaptation time, optokinetic nystagmus, welding fumes.

It is well known that welding fumes may produce harmful effects on humans. Some of these effects have been clearly demonstrated, especially those on the respiratory system. One effect not yet so well studied is "metal fume fever" with symptoms of fever, muscular weakness, and fatigue. These symptoms may perhaps be caused by toxicoallergic effects of the absorbed fumes on various organs of the body (10). There are also few reports on the acute and chronic effects on the central nervous system (CNS), ie, symptoms of headache, ocular disturbance, fainting, and difficulty in concentrating $(2,11)$. The rather vague symptoms, as well as the lack of

1 Department of Ophthalmology, Karolinska Hospital, Stockholm, Sweden.

Reprint requests to: Dr Claes-Johan Linde, Department of Ophthalmology, Karolinska Hospital, S-104 01 Stockholm, Sweden. reliable registration methods, make it difficult to discover and/or confirm a causal relation to welding fumes, especially with respect to acute effects.

The light sensitivity of an eye adapted to a certain luminous level decreases abruptly when the eye is exposed to a bright flash of light. The time that elapses from such an exposure until a certain object reappears is called the readaptation time (RAT). RAT varies with factors like the intensity of the flash of light used for light adaptation, stimulus contrast, and illumination level.

The RAT registered following glare is a result of processes in the CNS. These can be photochemical changes in the retina or disturbances in the flow and/or processing of the neuronal impulses in the retina or elsewhere in the visual pathway or cerebral cortex. 
An objective method for the measurement of RAT consists of determining the recovery time for optokinetic nystagmus after a bright flash of light. This method has earlier been used in studies on the effects of varying proportions of oxygen in

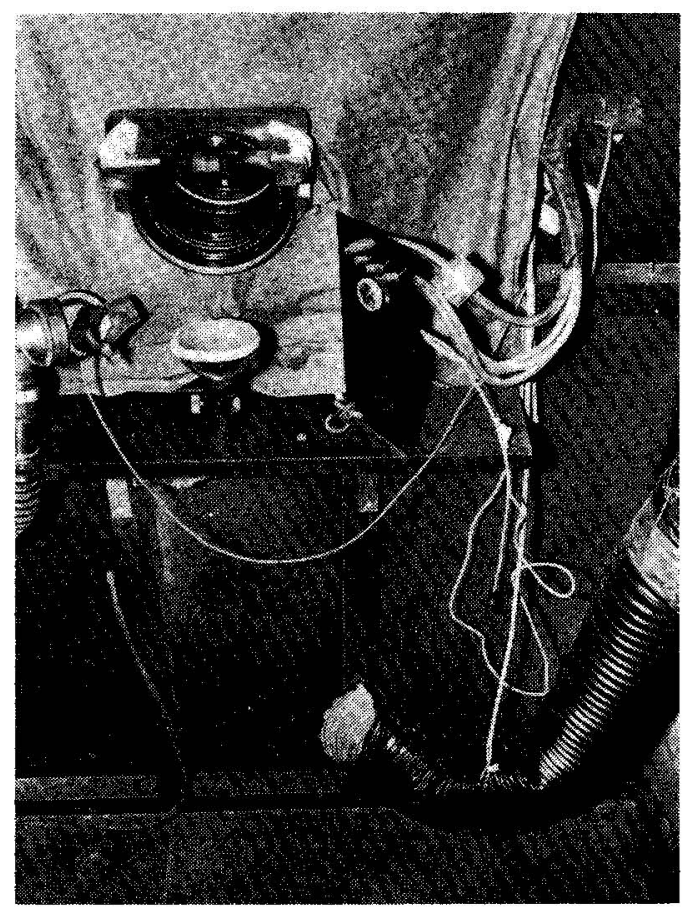

Fig 1. Apparatus for measuring readaptation time (RAT) during the inhalation of welding fumes. The subject was supported by the chin rest and looked at the stimulus object. The respiratory valve is on the left and the gas particle collector on the right. Welding fumes were introduced through the tube in the lower righthand corner.

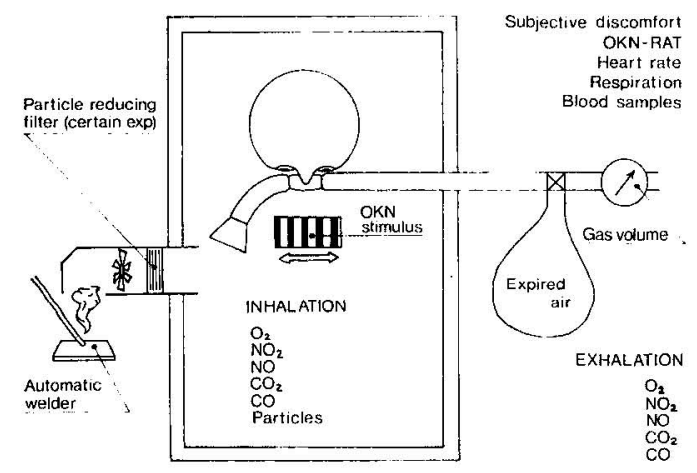

Fig 2. Schematic diagram of the apparatus used for recording readaptation time (RAT) and other parameters during the welding-fume experiments. inhaled air on the CNS and the effects of certain drugs $(1,4,14)$. The same method has been used in this investigation.

In the present work the effect of welding fumes from a number of electrodes in general use has been studied. Interviews with professional welders showed that they feel the greatest discomfort when using two types of electrodes, those containing copper and those containing fluorides. Fluorides are used in basic electrodes, but not in rutile electrodes. Therefore electrodes both with and without these components have been used.

As it is not known whether the substances causing discomfort occur in the gas phase or the particle phase of the fumes or in both, this problem has also been studied.

The aim of the project was to investigate the following: (i) the effects of welding fumes on ocular RAT, (ii) whether it is the gas phase, the particle phase, or both that affect RAT, and (iii) whether RAT changes caused by welding fumes can be correlated to the content of certain substances in the electrodes.

\section{Methods and materials}

RAT after a bright flash of light was determined from recordings of the arrest of optokinetic nystagmus. Optokinetic nystagmus consists of reflex pursuit and refixation movements. In connection with light adaptation, optokinetic nystagmus ceases but returns when the stimulus is again perceived. The optokinetic nystagmus stimulus used consisted of a vertical stripe pattern of alternating black and white bands. The square stimulus field covered approximately $25^{\circ}$ of the central part of the visual field. The mean luminance level of the stimulus was $10^{-4}$ $\mathrm{cd} / \mathrm{m}^{2}$, scotopic level. The contrast between white and black bands was 1.0 , and the angular dimensions of each band was $2.8^{\circ}$ horizontally. The light adaptation was produced with a xenon flash with a field luminance of $10^{4} \mathrm{~cd} / \mathrm{m}^{2}$ and a duration of $0.8 \mathrm{~ms}$. The field of light adaptation covered a larger part of the visual field than the optokinetic nystagmus stimulus. The flash was presented as a homogeneous white field. 
The optokinetic nystagmus recording was made with three electrooculographic electrodes, one attached to each temple and one to the forehead. After amplification the results were registered on a recorder.

During the experiments the subject was in a closed room with a volume of about $4 \mathrm{~m}^{3}$. In this room the apparatus for the optokinetic nystagmus stimulus and glare was placed in front of the subject (fig 1).

Welding fumes from an automatic welder placed outside the room were directed to below the subject's face and evacuated by exhaust ventilation through the ceiling of the room. When measurements of inhaled and exhaled gases were carried out, the subject breathed through a valve, type CAMP 20103, which has an extremely low flow-resistance. The experimental apparatus is schematically diagramed in fig 2 .

\section{Welding equipment}

The fumes were produced by automatically controlled arc-welding with coated electrodes. In these machines a motorized clamp guides the electrode towards the base metal. Power supply to the electrode generates an electric arc at its tip that fuses the electrode to the weld metal (metal formed from the electrode material after welding). In its manual form this method is the welding technique most used in Sweden. The automatic control kept the welding speed constant. The voltage across the arc was $30 \mathrm{~V}$ and the current for welding $160 \mathrm{~A}$.

\section{Filler metal}

Welding was carried out on unpainted, hot-rolled sheet metal, SIS steel 1312, 8 $\mathrm{mm}$ thick. However, in welding with electrode OK 94.25 (which has a high copper content), red brass (85\% copper, $5 \%$ zinc, $5 \%$ tin, $5 \%$ lead) must be used, as this electrode does not weld on to sheet metal.

The following types of electrodes (ESAB, Göteborg, Sweden) were used for the welding: OK 43.32, rutile (no fluorides); OK 48.15, basic (moderate fuming); OK 73.08, basic, copper- and nickel-alloyed (marked fuming); OK 73.68, basic '(similar to 73.08 but without copper); OK 92.58 , basic (low copper content); OK 94.25 basic (high copper content); OK $48.15-\mathrm{F}$, basic (without fluorides); and OK $43.32+\mathrm{F}$, rutile (addition of fluorides).

Fume data for the different electrodes are given in table 1, which also states the quantity of fumes and the largest components in the fumes. The content of the weld metal is shown in table 2. The total quantity of particles in the fumes from three of the electrodes is given in table 3.

Table 1. Fume data for different electrodes.a

\begin{tabular}{|c|c|c|c|c|c|c|}
\hline & \multicolumn{6}{|c|}{ Electrode } \\
\hline & $\begin{array}{l}\text { OK } 73.08 \\
\text { (basic) }\end{array}$ & $\begin{array}{c}\text { OK } 73.68 \\
\text { (basic) }\end{array}$ & $\begin{array}{l}\text { OK } 48.15 \\
\text { (basic) }\end{array}$ & $\begin{array}{c}\text { OK } 43.32 \\
\text { (rutile) }\end{array}$ & $\begin{array}{l}\text { OK } 92.58 \\
\text { (basic) }\end{array}$ & $\begin{array}{c}\text { OK } 94.25 \\
\text { (basic) }\end{array}$ \\
\hline Diameter (mm) & 4.0 & 4.0 & 4.0 & 4.0 & 4.0 & 4.0 \\
\hline Amount of fume $(\mathrm{g} / \mathrm{h})$ & 32.6 & 21.2 & 23.2 & 21.2 & 15 & \\
\hline Magnetic $(\%)$ & 25.5 & 20.5 & 21.2 & 36.5 & 9.0 & \\
\hline Manganese $(\%)$ & 4.9 & 2.8 & 3.2 & 4.8 & 1.4 & \\
\hline Fluoride total $(\%)$ & 21.3 & 19.0 & 18.4 & 0 & 7.4 & \\
\hline Lead $(\%)$ & 0.029 & 0.030 & 0.031 & 0.025 & 0.013 & \\
\hline Copper $(\%)$ & 0.580 & 0.063 & 0.038 & 0.037 & 0.04 & $4-5$ \\
\hline Chromium $(\%)$ & 0.010 & 0.008 & 0.013 & 0.051 & 0.010 & \\
\hline Nickel $(\%)$ & 0.051 & 0.211 & 0.004 & 0.004 & 7.50 & \\
\hline Vanadium $(\%)$ & 0.010 & 0.005 & & & & \\
\hline Cobalt $(\%)$ & 0.050 & 0.004 & & & & \\
\hline $\mathrm{NHL}\left(\mathrm{m}^{3} / \mathrm{h}\right) \mathbf{b}$ & 10,373 & 5,832 & 5,828 & 4,965 & 3,525 & \\
\hline Fume class & 3 & 2 & 2 & 2 & 2 & \\
\hline
\end{tabular}

a Values stated by manufacturer.

b $\mathrm{NHL}=$ nominal hygienic air requirement. 
Table 2. Normal analysis of metal welding with different types of electrodes.a

\begin{tabular}{lccccccccc}
\hline $\begin{array}{l}\text { Type of } \\
\text { electrode }\end{array}$ & Copper & Carbon & Silicon & Manganese & Nickel & Iron & Sulfur Phosphorus & Tin \\
\hline OK 73.68 & - & 0.06 & 0.3 & 0.7 & 2.4 & - & 0.01 & 0.01 & - \\
OK 92.58 & $<0.05$ & 0.7 & 0.7 & 0.6 & 55 & 43 & - & - & - \\
OK 73.08 & 0.4 & 0.08 & 0.35 & 1.0 & 0.6 & - & - & - & - \\
OK 94.25 & 91 & - & 0.7 & - & - & - & - & - & - \\
OK 48.15 & - & 0.1 & 0.6 & 0.9 & - & - & - & - & - \\
OK 43.32 & - & 0.1 & 0.4 & 0.5 & - & - & - & - \\
\hline
\end{tabular}

a Values stated by manufacturer.

Table 3. Filter content $(\mu \mathrm{g})$ after $65 \mathrm{~min}$ of welding.

\begin{tabular}{|c|c|c|c|}
\hline \multirow[b]{2}{*}{ Element } & \multicolumn{3}{|c|}{ Electrode a } \\
\hline & $\begin{array}{c}\text { OK } 43.32 \\
\text { (rutile) }\end{array}$ & $\begin{array}{c}\text { OK } 48.15 \\
\text { (basic) }\end{array}$ & $\begin{array}{c}\text { OK } 73.08 \\
\text { (basic) }\end{array}$ \\
\hline Aluminum & 4.3 & 20 & 18 \\
\hline Antimony & 0.2 & - & 0.2 \\
\hline Arsenic & 4.0 & 0.9 & 1.3 \\
\hline Lead & 1.9 & - & 6.2 \\
\hline Bromine & - & 0.4 & 0.5 \\
\hline Cesium & - & 8.08 & - \\
\hline Phosphorus & 10 & 0.4 & 0.5 \\
\hline Gallium & 0.7 & 0.9 & 14 \\
\hline Iron & 290 & 508 & 1,500 \\
\hline Calcium & 3.0 & - & - \\
\hline Potassium & 36 & 64 & 110 \\
\hline Silicon & 160 & 7 & - \\
\hline Cobalt & 0.6 & 0.6 & 0.4 \\
\hline Copper & 1.6 & 0.7 & 20 \\
\hline Chromium & 0.4 & - & 0.4 \\
\hline Magnesium & 1.1 & 7.2 & 7.1 \\
\hline Manganese & 170 & 130 & 400 \\
\hline Nickel & 0.5 & 0.3 & 1.4 \\
\hline Niobium & 0.2 & - & - \\
\hline Rhodium & 0.04 & - & - \\
\hline Rubidium & 0.6 & 1.9 & 0.5 \\
\hline Strontium & - & 0.1 & 0.2 \\
\hline Tin & 1.8 & - & 5.9 \\
\hline Titanium & 36 & 8.0 & 12 \\
\hline Vanadium & 0.8 & 0.2 & 0.6 \\
\hline Wolfram & 0.1 & 0.5 & - \\
\hline Zinc & 1.7 & 0.1 & 1.0 \\
\hline Total & 725.4 & 751.3 & $2,100.2$ \\
\hline
\end{tabular}

a Electrode diameter $4 \mathrm{~mm}$.

OK 73.08 and OK 48.15 were selected because they represent basic electrodes with marked and moderate fuming, respectively. OK 43.32 represents an electrode with rutile properties. The essential difference between rutile and basic electrodes is that rutile electrodes lack fluorides in the weld metal and hence in the welding fumes formed. The rutile electrodes also release titanium dioxide in the weld metal and into the fumes. Basic electrodes contain potassium and calcium, which give alkaline properties. OK 73.08 was used also to investigate the effect of the particle separation filter.

In the experiments carried out to ascertain the significance of copper, OK 73.08 and $\mathrm{OK} 73.68$ were used. Both are basic electrodes with a similar metal content, but there is no copper in OK 73.68. OK 94.25 is basic and has a very high copper content. OK 92.58 is also basic but contains very small amounts of copper.

The manufacturer supplied fume data for the basic electrode OK 48.15 and the rutile electrode OK 43.32 . On the basis of these data test electrodes of type OK 48.15, from which the fluorides had been removed, and electrodes of type 43.32, with the addition of fluorides, were made. The objective was to investigate the possible effects of the fluorides in the fumes.

\section{Analyses of gases in welding fumes}

Samples of gas were taken from the ambient air nearest the subject's mouth. Carbon dioxide was detected with analytic ampuls with reagents that change color on exposure to carbon dioxide. For the measurement of nitric oxide, nitrogen dioxide, and carbon monoxide direct-reading instruments with electrochemical detectors were used. Oxygen was evaluated with the help of a galvanic cell.

\section{Filter}

Particle separation was carried out with a mechanical glassfiber filter (type Camfil 
Absolute), which separates out $99.97 \%$ of particles $>0.3 \mu \mathrm{m}$ in size. The pressure drop through the filter was controlled from readings from a water column.

\section{Dust analyses}

The particles in the welding fumes were collected on a mechanical filter of cellulose acetate with a pore size of $0.8 \mu \mathrm{m}$. Collection was carried out in the subject's ambient air during the 65 -min welding period. The chemical elements in the fumes were analyzed by a mass spectrometry method. There was no separation according to particle size.

\section{Blood analyses}

Trace elements in blood samples obtained just before exposure to welding fumes and immediately afterwards were detected by a method based on energy-dispersive X-ray fluorescence (8). Analyses of blood gases were carried out by routine methods.

\section{Subjective discomfort}

Before the tests, which were usually carried out in the morning, the subjects were in good condition. During the welding period they were asked to estimate the degree of discomfort (headache, nausea, fatigue). For this estimate a scale graded from $0-10$ was used, 0 equaling no discomfort and 10 extreme discomfort.

\section{Subjects}

The subjects in this study were healthy male volunteers aged $26-32$ a and not professionally occupied with welding. The number of subjects varied from experiment to experiment because some of the tests were time-consuming and the supply of specially manufactured electrodes was limited.

\section{Experimental procedure}

Capillary and venous blood was obtained for gas and trace element analyses, respectively. The subject was then placed in the completely darkened test room. Preexposure values for inhaled and exhaled gases, respiratory volume, respiration and pulse rates were noted. The subject was allowed to adapt to the dark until the optokinetic nystagmus stimulus was clearly visible, which took about $10 \mathrm{~min}$. Five RAT measurements were then made at 1-min intervals; the average of these five recordings constituted the preexposure RAT. Exposure to welding fumes was then started and maintained for $65 \mathrm{~min}$. RAT was recorded after $5 \mathrm{~min}$ of welding and thereafter every 15th min. Inhaled and exhaled gases were analyzed with the same time interval. Respiratory volume was measured after $30 \mathrm{~min}$. Pulse and respiration rates were recorded continuously. After a lapse of $65 \mathrm{~min}$ new capillary and venous blood samples were taken.

The subject reported the degree to which he felt affected by the situation before exposure to the welding fumes, and then every 15 th $\mathrm{min}$.

During the exposure to welding fumes all measurements could be carried out without interrupting the welding or opening the room used for the experiments. This arrangement, together with the fact that the measurements were made halfway between the exchanges of electrodes in the automatic welder (about 35 electrodes were used for $65 \mathrm{~min}$ of welding), reduced the risk of possible alterations in fume concentration affecting the results.

The subjects were not aware of the type of electrode being welded or whether the fumes were filtered.

The experiments may be classified as follows: (i) the effects of fumes from basic or rutile electrodes, (ii) the effects of copper and fluorides in the welding fumes, (iii) the effects of a particle-reducing filter, and (iv) analysis of inhaled welding gases, welding-fume particles, trace elements in blood, and blood gases, and the recording of pulse, respiration rates, respiratory volume, and subjective indisposition.

\section{Accuracy of measurements and variations}

For each individual, variations in repeated RAT values under a certain test condition were small, but they had a tendency to increase somewhat towards the end of the tests. In earlier literature with the same recording procedure for $\operatorname{RAT}(4,14)$, a similar trend was seen. 


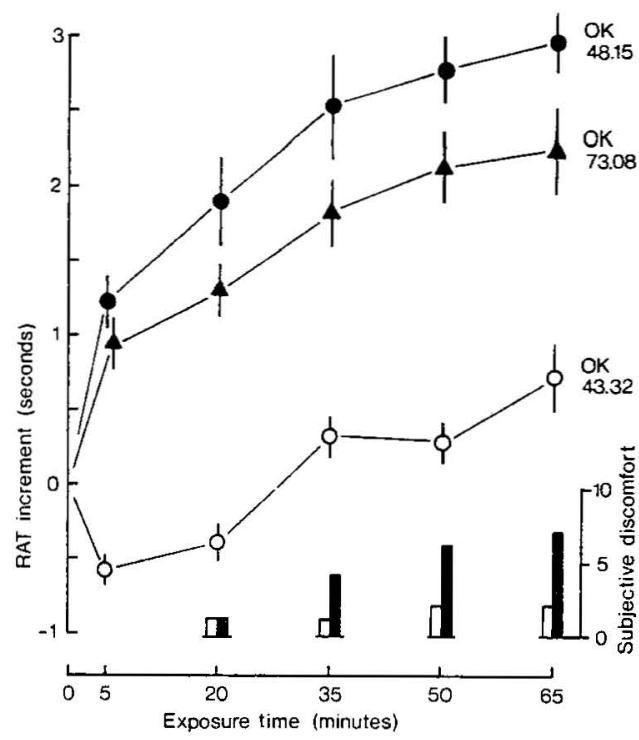

Fig 3. Change in readaptation time (RAT) as a function of length of exposure to welding fumes from basic electrodes OK 48.15 ( 9 subjects, filled circles) and OK 73.08 (12 subjects, triangles) and rutile electrode OK 43.32 (9 subjects, unfilled circles). Vertical bars indicate standard errors of the means $( \pm)$. (Subjective discomfort: $0=$ none, $10=$ extreme, with fumes from basic electrodes (filled column) and rutile electrodes (unfilled column).

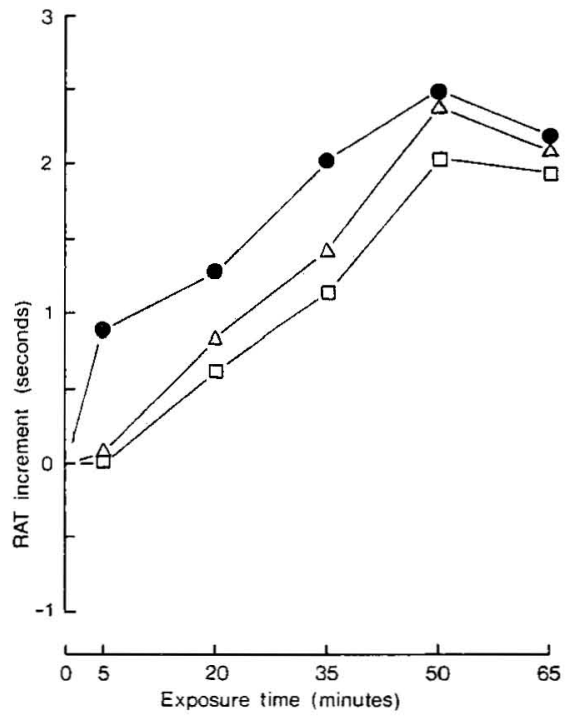

Fig 4. Change in readaptation time (RAT) as a function of length of exposure to welding fumes from basic electrodes (OK 48.15) of different diameters ( 3 subjects). (- $4.0 \mathrm{~mm}, \triangle 3.25 \mathrm{~mm}$, $\square 2.5 \mathrm{~mm}$ )
In the results, the mean of the subjects' RAT increments is presented with the standard error of the mean.

\section{Results}

\section{Readaptation time}

RAT changes were greatest during the later part of the experiment. Welding fumes from the rutile electrode (OK 43.32) produced a negligible effect on RAT that did not exceed $0.6 \mathrm{~s}$, ie, a prolongation of $6 \%$. But fumes from the basic electrodes (OK 48.15 and OK 73.08) caused a marked prolongation of RAT (fig 3). The maximum change in the RAT mean value was approximately $2.6 \mathrm{~s}$, ie, a prolongation of $35 \%$. Thinner basic electrodes, which emit a smaller amount of fumes, showed a RAT prolongation of the same order of magnitude (fig 4).

Fumes from basic electrodes with a different copper content in the metal, and thus a different copper content in the fumes, all gave a RAT prolongation of approximately $1.5 \mathrm{~s}$. The results did not show a greater RAT prolongation for the high copper content electrode than for those with a slight or no copper content (fig 5).

The fumes from the basic electrodes from which fluorides had been removed caused appreciably less RAT prolongation than did fumes from basic electrodes with a retained fluoride content (fig 6). The fumes from the rutile electrodes to which fluorides had been added did not, however, produce an increased RAT prolongation in comparison with fumes from the rutile electrodes with a fluoride-free design (fig 7).

In the experiments in which fumes from the basic electrode OK 73.08 were inhaled after they had passed through a particlereducing filter, the RAT prolongation was insignificant (fig 8).

\section{Welding gases}

In every experiment the content of carbon monoxide was approximately the same in the inhaled as in the exhaled gas. It increased for about the first $20 \mathrm{~min}$ of ex- 


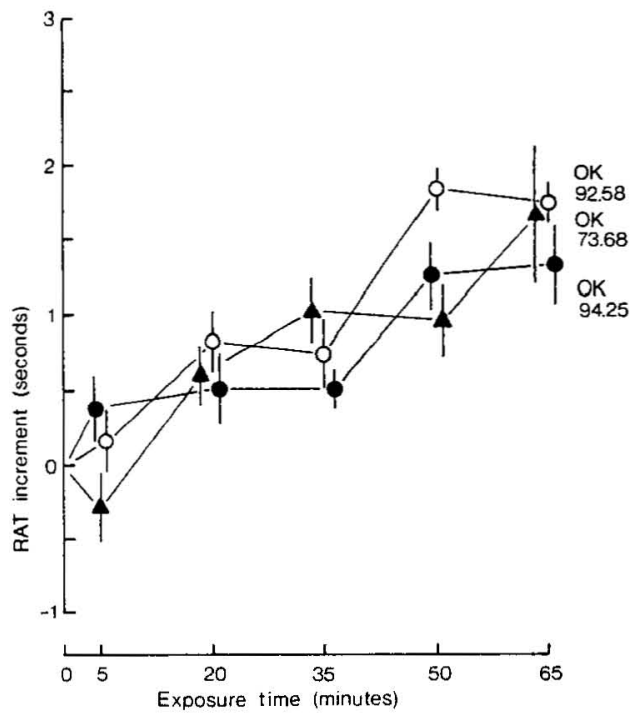

Fig 5. Change in readaptation time (RAT) as a function of length of exposure to welding fumes from basic electrodes providing a different copper content in the weld metal (6 subjects). Vertical bars indicate standard errors of the means. (OK $73.68=0 \% \mathrm{Cu}$, OK $92.58=0.05 \%$ $\mathrm{Cu}$, OK $94.25=91 \% \mathrm{Cu}$ )

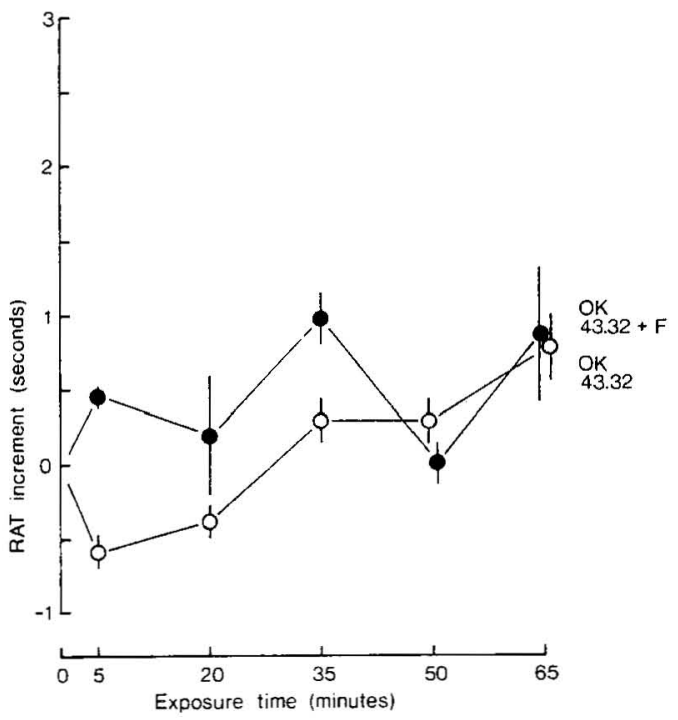

Fig 7. Change in readaptation time (RAT) as a function of length of exposure to welding fumes from electrode OK 43.32 (rutile) and test electrode OK $43.32+F$ with the addition of fluorides (3 subjects). Vertical bars indicate standard errors of the means ( \pm$)$.

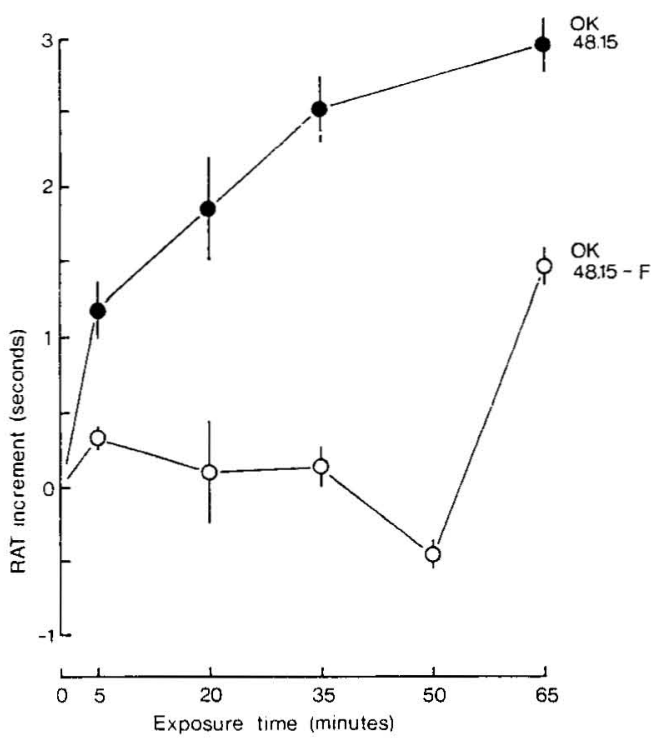

Fig 6. Change in readaptation time (RAT) as a function of length of exposure to welding fumes from electrode 48.15 (basic) and test electrode OK $48.15-F$ without fluorides (3 subjects). Bars indicate standard errors of the means $( \pm)$.

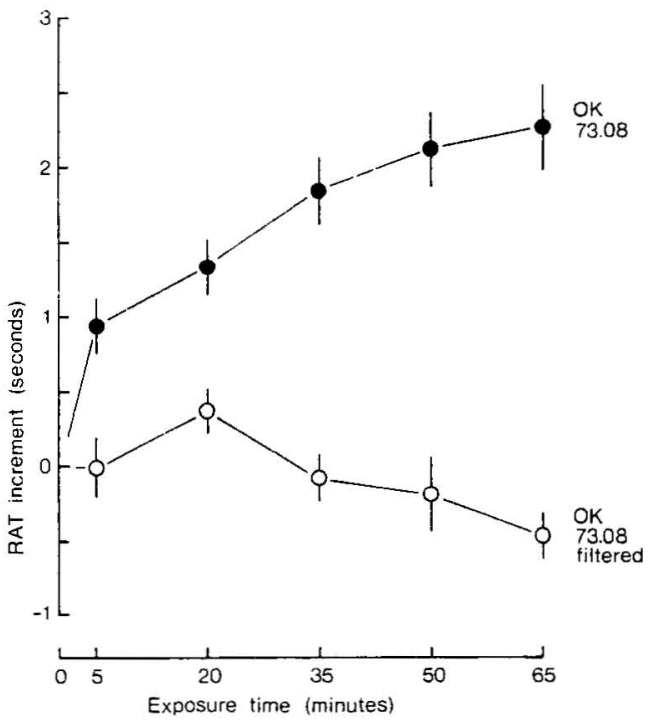

Fig 8. Change in readaptation time (RAT) as a function of length of exposure to welding fumes from basic electrodes OK 73.08 without (upper curve, 12 subjects) and with (lower curve, 14 subjects) a filter. Vertical bars indicate standard errors of the means $( \pm)$. 
posure to welding fumes and then remained almost constant for the rest of each experiment. During the last $30 \mathrm{~min}$ of each experiment the mean value for the content of carbon monoxide was $7-18$ ppm $\left(8-20 \mathrm{mg} / \mathrm{m}^{3}\right)$. This variation was not correlated to any particular type of electrode or to filtered or unfiltered welding fumes. No RAT effect could be observed to correlate to changes in the carbon monoxide content of the inhaled air.

The amounts of nitric oxide and nitrogen dioxide in the inhaled air were below the threshold limit values (TLVs) at all measuring points and were of the same order of magnitude for the different electrodes and for welding with or without a filter.

Throughout the different experiments the content of carbon dioxide in the inhaled air remained at a constant level of about $500 \mathrm{ppm}\left(900 \mathrm{mg} / \mathrm{m}^{3}\right)$, which is only one-tenth of the TLV.

Neither was the oxygen content of the inhaled air affected by exposure to welding fumes; in all tests it showed the concentration found in normal air.

\section{Particles in welding fumes}

From the fumes of each of the two basic (OK 48.15 and OK 73.08) and one rutile (OK 43.32) electrode, the total content of constituents collected on filters is shown in table 3. The filters were placed in the ambient air of the subject for the $65 \mathrm{~min}$ of welding. Compared with the content of the fumes from each of the other two electrodes, the sample of fumes from the basic electrode OK 73.08 contained nearly three times the amount of particles. The difference between the rutile electrode and the two basic electrodes lay mainly in the content of aluminum, iron and magnesium. The copper content in the fumes from the rutile electrode was not lower than that in the fumes from one of the basic electrodes. The concentrations of manganese were the same in the fumes from basic and rutile electrodes. TLVs were not exceeded in any case.

It was not possible to measure the samples from the filters in the ambient air in those experiments in which the welding fumes had first passed through a particleseparation filter because of the uneven distribution of particles on the filters.

\section{Trace elements in blood}

The changes in the blood concentrations of the trace elements after $65 \mathrm{~min}$ of exposure to welding fumes were so small that it was not possible to show any significant differences. All values measured were within normal limits.

\section{Pulse and respiration}

Throughout the experiments the pulse rate of a subject remained at the resting rate. The initial value for the respiration rate similarly remained unchanged during welding, and the respiratory volume remained constant at approximately 10 $1 / \min$.

\section{Blood gases}

The partial pressure of carbon dioxide, base excess, standard bicarbonate, hemoglobin, partial pressure of oxygen in arterial blood, carboxyhemoglobin, and $\mathrm{pH}$ values showed only small changes. The changes observed were well within normal variations.

\section{Discomfort}

The discomfort experienced by the subjects during exposure to welding fumes was reported as greater for fumes from the basic electrodes than for those from the rutile ones. Unfiltered fumes caused more discomfort than filtered fumes. The degree of discomfort increased parallel with increasing RAT prolongation (fig 3). Discomfort was slight in all cases and took the form of irritation of mucous membranes, slight nausea and headache.

\section{Discussion}

It is well known that welding fumes may cause acute discomfort. Some of the discomfort is due to the effect of the fumes on the respiratory system, but other symptoms, such as nausea, visual disturbance and difficulty in concentrating, have been attributed to effects on the CNS. No objective measurements of such 
effects on the CNS have been reported earlier. In the present investigation measurements of recovery of visual function after a bright flash of light, ie, ocular RAT, have proved useful in this connection. The method is relatively simple and is accurate and reproducible to a high degree.

In the tests carried out in the present study the welding fumes from rutile welding electrodes do not appear to have had any effect on RAT, while the fumes from basic electrodes cause a distinct prolongation of RAT (fig 3). The amount of fumes produced varies with the different types of electrodes. Thinner electrodes, which give off fewer fumes, were however found to produce an effect on RAT of about the same degree as that caused by the thicker electrodes (fig 4). The amount of fumes has therefore not been considered important in relation to RAT.

Since the fumes from copper-alloyed basic electrodes are reputed to be more irritating than those from other basic electrodes, some experiments were aimed at determining the possible importance of copper in the prolongation of RAT. The present results (fig 5) show that the role played by copper is not significant.

The importance of the fluorides in this connection was then examined. The characteristics of basic electrodes stem from their content of calcium and fluorides, which distinguishes them from rutile electrodes. The inhalation of fluorides may cause toxic effects in animals and man. After long-term exposure animals, for instance, show damage to the CNS (12). Our results show that the fluoride content in a basic electrode is a necessary constituent if the fumes are to produce definite RAT prolongation, whereas fumes from rutile electrodes to which the same amount of fluoride (fluorspar) has been added affect RAT only slightly.

There may be several explanations for this unexpected result. Since basic and rutile electrodes do not have the same chemical composition - for example, the basic electrodes contain a greater amount of calcium, while the rutile electrodes have a greater amount of oxides - the rutile electrode with its added fluorides may perhaps form fluoride compounds quite different from those produced by a basic electrode. The fact that different fluoride compounds have different degrees of solubility and absorption and thus different toxicities (7) may be of decisive importance to the occurrence of RAT prolongation. Another factor that must be considered is the size of the particle carrying the fluoride. Studies have been published in which the potassium salts in the electrode have been exchanged for sodium salts; the resulting fumes contained an increased quantity of larger particles (5, 13). These authors also found that the incidence of metal fume fever and other symptoms then diminished, presumably because of a less systematic absorption of fumes in which large particles predominate. Since the rutile electrode contains only a small amount of potassium, added fluoride may conceivably become bound to substances that form larger particles that show less systemic absorption and thus do not influence RAT.

These problems can be clarified by an accurate determination of the chemical composition of welding fumes; such a determination was not possible in the present investigation.

When particles, mostly larger than 0.3 $u \mathrm{~m}$, are filtered from the welding fumes, no RAT prolongation occurs (fig 8); this finding indicates that the RAT prolongation effect is due to this particle phase and that the substance affecting RAT should be sought there.

The determination of the kinds of particles or substances causing RAT prolongation presents great difficulties. The total amount of particles plays no decisive role (table 3), nor does the fume analysis carried out in this investigation (fluorides were not analyzed) provide any grounds for suspecting a particular substance. It is also possible that a combination of several substances may be responsible for the effect on RAT.

A conceivable cause of RAT prolongation during exposure to welding fumes might be anoxemia since the welding arc consumes oxygen. [Tengroth et al (14) showed that low oxygen concentration in the breathing air caused a prolongation of RAT.] The results of the present study do not support this hypothesis: the oxygen value in the inhaled air remained constant throughout the experiments. 
A subsidiary problem is whether the RAT changes reflect changes in the concentration of trace elements in the blood. In an earlier investigation with the same method of analysis as the present study, no appreciable difference was found between welders and nonwelders with respect to most of the trace elements in the blood (9). But it was found that welders had a somewhat lower copper content in their blood and a markedly increased zinc content when compared to nonwelders. In the present investigation, in which the acute effects of welding fumes have been studied, it was not possible to observe any similar change in the copper and zinc content of the blood. Nor were abnormal values for any other trace elements in blood observed.

The filter used in this study mainly separates particles of $0.3 \mu \mathrm{m}$ or more in diameter. These particles seem to cause the RAT changes. Particles smaller than $5 \mu \mathrm{m}$ can pass into the pulmonary alveoli (6) and are phagocytized into the blood stream. Thus determining the size and content of the particles in the welding fumes should make it possible to demonstrate even a small increase in their plasma concentration. This is suggested as analysis of a limited number of previously known substances can be performed with higher accuracy.

The changes in RAT obtained after exposure to welding fumes from basic electrodes were of the same order of magnitude as the RAT prolongation observed after intake of a therapeutic dose of oxazepam. The drug has a tranquillizing effect and prolongs reaction time (1). It is probable that a prolongation of RAT reflects a slowing-down effect on the CNS. RAT prolongation is also correlated to discomfort from nausea and headache, probably stemming from the CNS. In all our present experiments the subject was at rest. It can be assumed that an increased work load, with its accompanying increased inhalation of welding fumes, may result in a greater effect on the welder's CNS and thus also on RAT. This assumption is supported by results from preliminary field experiments (Högman, personal communication).

Despite the development of new types of electrodes and welding methods, basic electrodes will, because of their superior welding properties, continue to be indispensable for a number of purposes (3). Therefore further research is needed to evaluate the effect of fumes from basic electrodes on welders' health. The experiments conducted in this study show that even brief exposure to welding fumes can cause acute symptoms and an objectively measureable effect on the CNS. The effects correlated with the particle phase of the fumes. It thus seems that by determining how ocular RAT is affected by exposure to welding fumes, it may be possible to contribute to knowledge on health risks in the welder's environment.

\section{Conclusions}

1. The recording of RAT changes appears to be a useful method for objectively measuring the acute CNS effects caused by welding fumes.

2. Welding fumes from basic electrodes cause appreciable RAT prolongation.

3. Welding fumes from rutile electrodes cause no demonstrable RAT prolongation.

4. RAT prolongation resulting from exposure to welding fumes from basic electrodes is comparable to that occurring after the administration of a therapeutic dose of oxazepam.

5. Analysis of the fume particles collected on filters has not given any indication as to which substances in the fumes cause a prolongation of RAT.

6. Fumes from basic electrodes with a high content of copper do not result in a greater prolongation of RAT than the fumes from electrodes without copper.

7. Welding fumes from a basic electrode after particle separation filtering (particles $>0.3 \mu \mathrm{m}$ ) cause no significant RAT prolongation.

8. The results show that fluorides might cause the prolongation of RAT after exposure to welding fumes, at least those in the fumes from basic electrodes. 
9. The increasing discomfort, such as headache and nausea, experienced by those exposed to welding fumes correlates with an increasing prolongation of RAT.

10. Serum analysis of trace elements does not show any specific trace element as the cause of RAT prolongation. All the measured values fall within the normal limits of variation.

\section{Acknowledgments}

I am greatly indebted to $\mathrm{Mr} B$ Högman, research engineer, and Ms A Larnemark, a nurse, for their skillful assistance during the experiments. I also wish to thank the personnel at the Department of Welding Technology, The Royal Institute of Technology, Stockholm, Sweden, for their very valuable technical help.

The study has been supported by the Swedish Work Environment Fund.

\section{References}

1. Bergman $\mathrm{H}$, Borg $\mathrm{S}$, Högman $\mathrm{B}$, Larsson H, Linde C-J, Tengroth B. The effect of oxazepam on ocular readaptation time. Acta ophthalmol 57 (1979) 145-150.

2. Ege P. Svejserög additionsformeln, begrundelse, de medicinska aspekter. Svejsning 2 (1975) 37-38.

3. Granjon ML, Buchup $\mathrm{H}$, Challen PJR, Frant R, Gerhardsson G, Makovicka L,
Vinter G. Hygienic aspects of welding with basic electrodes. Weld world 12 (1972) 20 -24 .

4. Högman B, Bergman H, Borg S, Eriksson $\mathrm{T}$, Goldberg $\mathrm{L}$, Linde $\mathrm{C}-\mathrm{J}$, Tengroth $\mathrm{B}$. Readaptation time after photo stress: Alcohol induced acute and postalcohol "hangover" changes in ocular readaptation time. Psychopharmacology 53 (1977) 165-167.

5. Kawada $K$, Iwano $K$, Nagai $N$, Kimura $S$. Experimental studies on the harmfulness of basic type welding electrodes and on their improvement. International Institute of Welding, 1964. (Doc VIII-197-64).

6. Leithe $W$. The analysis of air pollutants. Ann Arbor, MI 1971.

7. Nakamara I, Takizawa Y. Effects of fluorides on respiratory system of rat. J jpn soc air pollut 10 (1975): 4, 479.

8. Rindby A. Energidispersiv röntgenfluorescens-analys. Internal report Fysiska Institutionen, Chalmers tekniska högskola, Göteborg 1975.

9. Rindby A, Selin E, Wilhelmsson L. Spårelementanalys av svetsrök och blodserum. Götaverkens medicinska råd, Göteborg 1975. (Rapport nr 1975: 1).

10. Ross DS. Metal fume fever. $J$ soc occup med 24 (1974) 125-129.

11. Ross DS, Parkes LR, Arc welding - the health aspects. Metal mater technolog April (1975) 191-194.

12. Sadilova MS, Selyankina KP, Shturkina OK Experimental studies on the effect of hydrogen fluoride on the central nervous system. Hyg sanit (USSR) 30 (1965) 155166.

13. Sevár S, Pantücek M. Verification of the japanese basic electrode type LBM-52 compared with the czechoslovak basik electrode E-44.83. International Institute of Welding, 1966. (Doc VIII-253-66).

14. Tengroth B, Högman B, Linde C-J, Bergman $H$. Readaptation time after photo stress: Readaptation time as a function of oxygen concentration. Acta ophthalmol 54 (1976) $507-516$ 